\title{
Solid-state electrochemical behavior of Keggin-type borotungstic acid single crystal
}

\author{
Lidia Adamczyk • Krzysztof Miecznikowski
}

Received: 19 November 2012 /Revised: 17 December 2012 / Accepted: 19 December 2012 /Published online: 4 January 2013

(C) The Author(s) 2013. This article is published with open access at Springerlink.com

\begin{abstract}
We demonstrate the electrochemical characteristics of the, poorly described in the literature, mixed-valence proton conducting solid borotungstic acid single crystal, $\mathrm{H}_{5} \mathrm{BW}_{12} \mathrm{O}_{40} x \mathrm{H}_{2} \mathrm{O}$, in the absence of liquid electrolyte phase. We performed electrochemical measurements in an all-solid cell with a gold fiber ultramicrodisk (diameter 10, 25 , and $40 \mu \mathrm{m}$ ) working electrode, a silver semi-reference disk electrode, and a glassy carbon ring counter electrode. Diagnostic experiments at different scan rates aimed at probing the model of mass transport and potential kinetic limitations. Such bulk parameters as the effective diffusion coefficient of charge propagation and the concentration of mixed-valence redox centers were determined by two methods. The first method is based on the analysis of both Cottrellian and steady-state currents (the mixed-regimes method), and the second method provides the true diffusion coefficient (transport coefficient free of the migration influence) for both the substrate and the product of the electrode reaction. Together, these methods constitute a double potential step chronoamperometry experiment. The data obtained with these electrochemical experiments (effective diffusion coefficients, concentration of mixed-valence redox centers, etc.) can support the results obtained with other techniques (XRD, FTIR, and TGA).
\end{abstract}

Keywords Borotungstic acid · Single crystal $\cdot$ Redox reactions $\cdot$ Reversible electrochemical charging $\cdot$ Concentration of mixed-valence sites $\cdot$ Diffusion coefficient

\footnotetext{
L. Adamczyk

Department of Materials and Process Engineering and Applied

Physics, Czestochowa University of Technology,

42-200 Czestochowa, Poland

K. Miecznikowski $(\bowtie)$

Department of Chemistry, University of Warsaw,

02-093 Warsaw, Poland

e-mail: kmiecz@chem.uw.edu.pl
}

\section{Introduction}

Electrochemistry in the absence of external electrolyte is important because of its potential applications in different fields, including catalysis, materials science, and medicine $[1,2]$. The materials used for solid-state voltammetry should contain not only reactive redox species, through which fast reversible electron transfer is possible, but also fairly large amounts of mobile counter cations to keep the electroneutrality. Such materials can have potential application as charge storage in batteries and supercapacitors [3], electrochromic devices [4], corrosion protection [5, 6], medicine [7], and fuel cell research [7-15]. The important physicochemical parameters, such as porosity, degree and type of solvation, effective diffusion coefficient of charge propagation, concentration of redox species, should be taken into account during evaluation and selection of solid electrolytes.

Among the important requirements for a material to reveal electroactivity in solid, rigid, or semirigid state, in the absence of external liquid electrolyte, essential is the existence of mixed-valence redox centers and mobile charge-compensating ions [16-20]. Moreover, to minimize such parameters as ohmic resistance and migration effect, the concentration of charged species, like mobile ions and electrons, should be fairly large in the system. Examples of the mixed-valence inorganic bulk redox systems utilized in solid-state voltammetry are Keggin-type polyoxometalates (POMs), such as heteropolyacids of tungsten or molybdenum [21-26]. Generally, Keggin-type polyoxometalates have a central $X_{4}(X=\mathrm{B}, \mathrm{Si}, \mathrm{Ge}, \mathrm{P}, \mathrm{As})$ tetrahedron surrounded by $12 \mathrm{MO}_{6}$ octahedrons arranged in four groups of three-octahedral subunits, $\mathrm{M}_{3} \mathrm{O}_{13}$. These four groups are linked by their corresponding edges to each other and to the central $\mathrm{XO}_{4}$ tetrahedron $[1,2,27]$. The overall POMs charge depends on its heteroatoms and the nature of transition metals. Although the overall charge of the compound is negative, the oxidized metallic centers are generally external 
electrons acceptors, which does not cause major changes in the geometric structure, and take part in a wide variety of redox reactions. The coordination of metallic centers with large amount of $\mathrm{O}^{2-}$ species leads to formation of extremely ionic structures. From electrochemical point of view, in this type of system, 4 of the 12 tungsten (VI) or molybdenum (VI) atoms can be reversibly reduced to tungsten (V) or molybdenum $(\mathrm{V})$, respectively.

Up to now, the electrochemical behavior of POMs has been studied in many environments, such as aqueous solution [28, 29] or ionic liquid [30-33]. POMs have been studied as monolayers or organic-inorganic hybrids in contact with different supporting electrolytes [34, 35], and as single crystals in the absence of external liquid phase [21-26]. The electrochemical analysis of the most popular Keggin-type POMs (phosphotungstate and tungstosilicate) in the presence of acidic solution revealed three reversible reduction peaks originating from two one-electron processes followed by one two-electron process [17, 21, 22, 36]. Similar electrochemical behavior was described when these compounds were introduced into organic polymers or a silica matrix [6, 23, 24, 37-41]. Kulesza et al. [21, 22, 25] studied solid-state electrochemistry of these heteropolyacids and showed that the electrochemical behavior of both acids was almost the same as the behavior observed in solutions, namely: well-separated and reversible reduction peaks. Moreover, by combining various electroanalytical techniques, they found that these single crystals are characterized by high effective diffusion coefficients and large concentrations of mixed-valence redox centers (W or Mo) $[21,36]$.

In the present work, we performed a very limited, solely electrochemical characterization of a single crystal of borotungstate polyoxoanions in the absence of external liquid electrolyte. Investigation of boron-centered tungsten-oxygen heteropolyanions is necessary and very interesting considering their potential values. Boron is an electron-deficient element, which can form either trigonal or tetrahedral coordinations. Structure analysis of the $\alpha-\left[\mathrm{BW}_{12} \mathrm{O}_{40}\right]^{5-}$ Keggin anion reveals a central, regular $\{\mathrm{BO} 4\}$ unit, in agreement with 11B solid-state NMR data [42-44]. According to our previous work [25, 26, 45], application of electroanalytical approaches allow us to determine both the concentration $\left(C_{0}\right)$ of redox centers and the apparent diffusion coefficient $\left(D_{\text {app }}\right)$ for a single crystal of silicotungstic, phosphotungstic acids, or Prussian Blue in a sol-gel matrix, by solving a system of two equations with two unknowns $\left(D_{\text {app }}\right.$ and $\left.C_{0}\right)$. Moreover, the obtained apparent diffusion coefficients were compared with the values of the real diffusion coefficient (transport coefficient free of migration influence) calculated by using the analysis of transient currents in the double potential step chronoamperometric experiment (DPSC) $[46,47]$. The great advantage of this method is that determination of the electroreactant's diffusion coefficient and concentration can be performed independently. The results that we obtained for borotungstic acid allow us to tell more about the mechanism of charge propagation.

\section{Experimental}

$\mathrm{H}_{5} \mathrm{BW}_{12} \mathrm{O}_{40} x \mathrm{H}_{2} \mathrm{O}\left(\mathrm{BW}_{12}\right)$ was synthesized according to the reference [48] and characterized by FTIR, powder X-ray diffraction and TGA. A single crystal of borotungstic acid $\left(\mathrm{BW}_{12}\right)$ was prepared as follows: a known amount of $\mathrm{BW}_{12}$ $(3 \mathrm{~g})$ was dissolved in $5 \mathrm{ml}$ of water in a beaker to obtain a highly concentrated solution. Next, the clear, concentrated solution of $\mathrm{BW}_{12}$ was put aside for a week at room temperature in a closed beaker to allow slow crystallization. The crystallization process for each single crystal of $\mathrm{BW}_{12}$ was repeated three times. Each time before use, gold ultramicrodisk electrodes (diameter of 10,25 , and $40 \mu \mathrm{m}$ ) were activated by briefly polishing with alumina powder on a wet pad (grain size $0.05 \mu \mathrm{m}$, Buehler, Chicago, IL). After polishing, the electrodes were thoroughly rinsed with deionized water. Solutions were prepared using double distilled water that was further purified with a Millipore Milli-Q system. All measurements were performed at ambient temperature, $20 \pm 2{ }^{\circ} \mathrm{C}$.

Electrochemical measurements were performed using an electrochemical analyzer, model $750(\mathrm{CH}$ Instruments, Austin, TX) in three electrode configurations, almost identical to those proposed previously by Kulesza [16]. The electrochemical cells were kept in a Faraday cage during the measurements to minimize the electric noise. In the cell that we used, the single crystal of $\mathrm{BW}_{12}$ was placed in the center of the cell, between the surface composed of two electrodes (reference/semireference system [silver/silver oxide electrode]), the counter (glassy carbon ring), and the working electrode (gold ultramicrodisk). In order to provide good repeatability (within $5 \%$ ), the results were based on eight electrochemical experiments with independently prepared samples. To avoid partial dehydration of the single crystal of $\mathrm{BW}_{12}$ glass tubing was used to protect it. $\mathrm{X}$-ray diffraction (XRD) patterns of the $\mathrm{BW}_{12}$ powder were recorded using a Bruker D8 Discover system operated with a $\mathrm{Cu}$ lamp (1.54 $\AA$ ), and a Vantec (linear) detector $(k=1.5406 \AA)$. Infrared spectrometry was performed on the sample powder compressed with $\mathrm{KBr}$ into pellets with a Shimadzu 8400 FTIR spectrometer over the range of $400-4,000 \mathrm{~cm}^{-1}$. Potassium bromide was chosen because it shows no infrared absorption in that wavelength range (the observed peaks belong solely to the borotungstic acid sample). Thermogravimetric analyses (TGA) were carried out in the flow of $\mathrm{N}_{2}$ on a Calvet TG-DSC 111 SETARAM instrument with heating rate of $10{ }^{\circ} \mathrm{Cmin}^{-1}$, in the range $20-650{ }^{\circ} \mathrm{C}$. 


\section{Result and discussion}

FTIR experiment

To elucidate the structure and identify the synthesized borotungstic acid, FTIR spectra were performed (Fig. 1). Four characteristic bands of the Kegging-type structure of borotungstic acid were observed in the range $700-1,000 \mathrm{~cm}^{-1}$. The peaks at 960,917, 810, and $747 \mathrm{~cm}^{-1}$ are attributed to $\left(\mathrm{W}-\mathrm{O}_{\mathrm{d}}\right),\left(\mathrm{W}-\mathrm{O}_{\mathrm{a}}\right),\left(\mathrm{W}-\mathrm{O}_{\mathrm{b}}\right)$, and $\left(\mathrm{W}-\mathrm{O}_{\mathrm{c}}\right)$ stretching vibrations, respectively. These results indicate that the synthesized borotungstic acid has a basic Keggin-type structure, which is consistent with previous literature data [49-52]. Furthermore, the FTIR spectra showed three additional bands at $504,1,004$, and $1,410 \mathrm{~cm}^{-1}$ that can originate from the vibrations of the central tetrahedral $\mathrm{BO}_{4}$ group [53]. The peaks at 504 and $1,004 \mathrm{~cm}^{-1}$ are assigned to the maximum of the $\mathrm{W}-\mathrm{O}-\mathrm{B}$ stretching mode for $\mathrm{BW}_{12}$, and the peaks at $1,410 \mathrm{~cm}^{-1}$ can be attributed to the asymmetric $\mathrm{B}-\mathrm{O}$ stretching vibration.

\section{Thermogravimetric analyses}

The TG plot (Fig. 2) of borotungstic acid shows a three-step weight loss in the temperature range $20-650{ }^{\circ} \mathrm{C}$ and gives a total weight loss of $17.5 \%$. The first region of the thermal dehydration of $\mathrm{BW}_{12}$, from 20 to $175{ }^{\circ} \mathrm{C}$, results from the loss of non-coordinated water molecules $(13.7 \%)$. The second region $\left(175-345^{\circ} \mathrm{C}\right)$ is likely to relate to the loss of the coordinated water molecule $(2.9 \%)$. The weight loss of $0.9 \%$ observed in the last step (in the range of 345 to

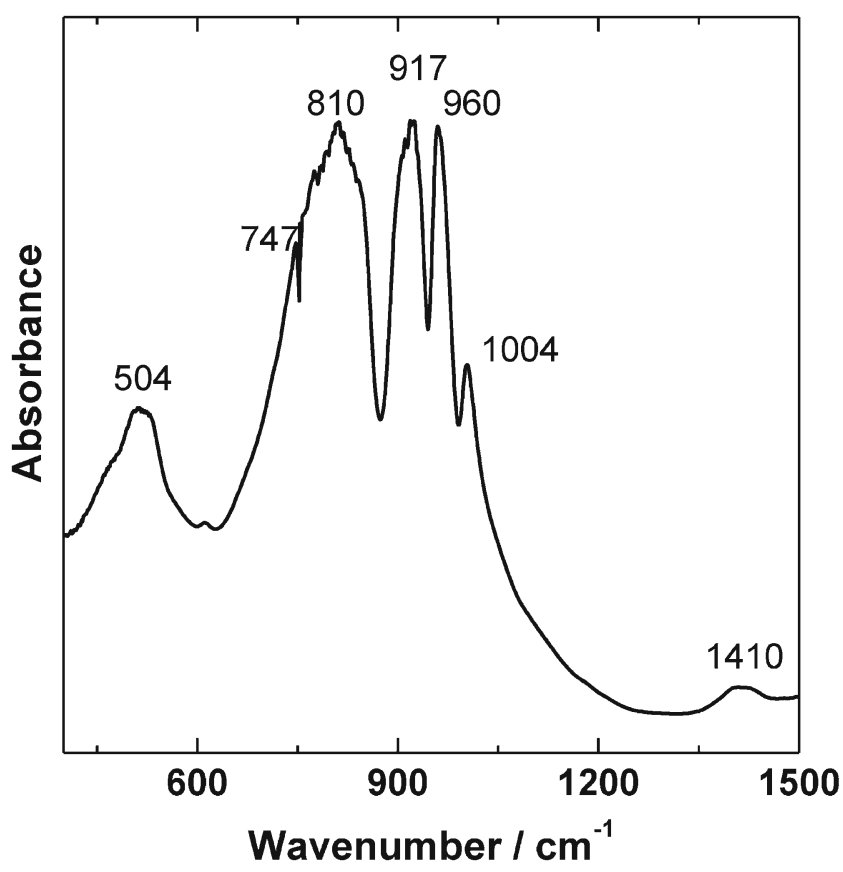

Fig. 1 Infrared (FTIR) spectra of $\mathrm{H}_{5} \mathrm{BW}_{12} \mathrm{O}_{40} x \mathrm{H}_{2} \mathrm{O}$

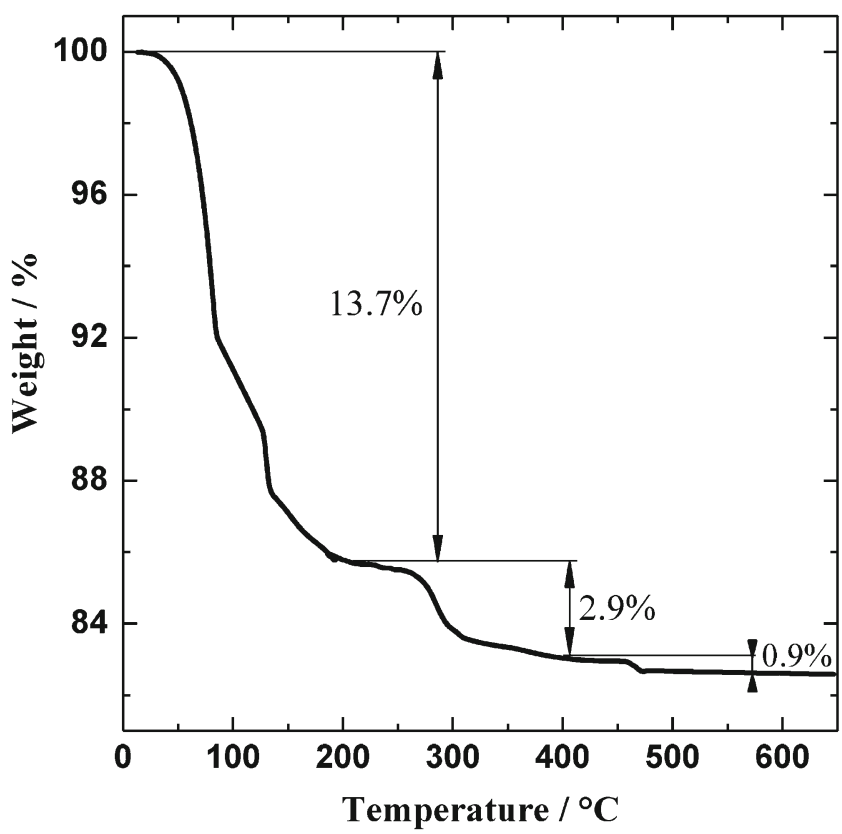

Fig. 2 Thermogravimetric curve for $\mathrm{H}_{5} \mathrm{BW}_{12} \mathrm{O}_{40} x \mathrm{H}_{2} \mathrm{O}$ under nitrogen

$650{ }^{\circ} \mathrm{C}$ ) is attributed to the release of the remains of the crystalline water molecule and the decomposition of polyoxometallate [53-55].

XRD analysis

Figure 3 illustrates X-ray powder diffraction patterns of borotungstic acid and shows only one phase. The strongest signals are clearly seen at 23-24 $2 \theta$. The diffraction peaks

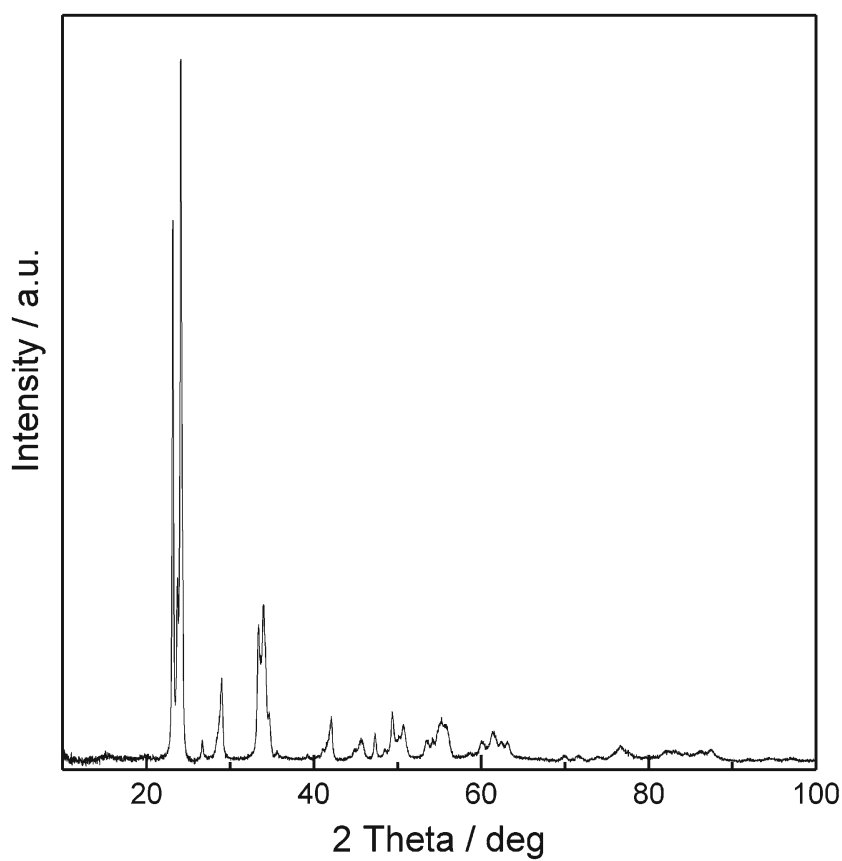

Fig. $3 \mathrm{XRD}$ pattern of $\mathrm{H}_{5} \mathrm{BW}_{12} \mathrm{O}_{40} x \mathrm{H}_{2} \mathrm{O}$ powders 
located at the values of $20-60^{\circ}$ are ascribed to the borotungstic acid hydrates $\left(\mathrm{BW}_{12}\right)$ with a Keggin structure. No other reflection signals coming from any other crystal phases were observed. It is evident, upon comparison with the data obtained by FTIR that $\mathrm{BW}_{12}$ has a Keggin structure.

Diagnostic cyclic voltammetric experiments

A typically shaped response of a single crystal of borotungstic acid $\left(\mathrm{H}_{5} \mathrm{BW}_{12} \mathrm{O}_{40} x \mathrm{H}_{2} \mathrm{O}\right)$, recorded at two extreme time regimes at a slow, (a) $4 \mathrm{mVs}^{-1}$, and at a fast, (b) $50 \mathrm{Vs}^{-1}$, scan rates is shown in Fig. 4. In order to limit the amount of our data, we decided to concentrate on the first two, most positive redox sites of $\mathrm{BW}_{12}$. In view of the previous work on a similar class of compounds [22], it seems plausible that these well-defined peaks of comparable size refer to two one-electron reversible redox processes. The wave-shaped response obtained at the slowest scan rate used, $\left(4 \mathrm{mV} \mathrm{s}^{-1}\right)$, as seen in Fig. 4a, indicated that the spherical mass transport prevailed, and the area of the sphere was much larger than the electrode surface. The current appearing in the reverse scan has retraced almost identically the spectrum recorded in the forward scan.

The solid-state voltammetric response of a single crystal of $\mathrm{BW}_{12}$ was significantly different when the fastest scan rate, $50 \mathrm{Vs}^{-1}$ (i.e., a short-time experiment), was used, as shown in Fig. 4b. It is apparent from the cyclic voltammetric analysis that the system is characterized by a typical peak-shaped response. Such characteristic behavior is related to the dimensionless time

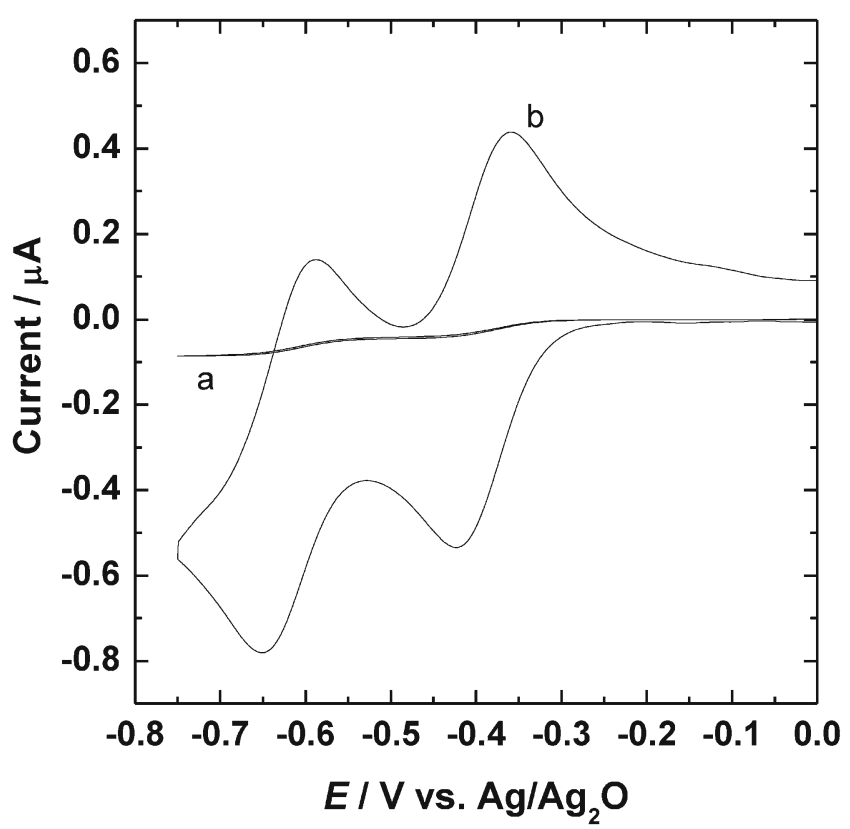

Fig. 4 Solid-state voltammetric responses of $\mathrm{BW}_{12}$ single crystal at (a) $4 \mathrm{mVs}^{-1}$ and (b) $50 \mathrm{Vs}^{-1}$. Au microelectrode radius: $5 \mu \mathrm{m}$ parameter $\tau$ that represents the square of the ratio of the apparent or effective diffusion coefficient to the radius of the electrode $\left(4 D_{\text {app }} t / r^{2}\right)$ [56, 57]. Small values of the parameter, $\tau \ll 1$, correspond to short times in the experiment (fast scan rate), in which the diffusion field is small compared to the electrode radius (planar diffusion). On the other hand, large values of $\tau(\tau \gg 1)$ correspond to long times in the experiment (slow scan rate), when the spherical diffusion field has had time to expand well beyond the electrode dimension (radial diffusion). In the latter case, the limiting steady-state current, $I_{\mathrm{ss}}$, is given by:

$I_{\mathrm{ss}}=4 n F D_{\mathrm{eff}} C_{\mathrm{o}} r$

where $D_{\text {eff }}$ is the effective diffusion coefficient (a combination of physical diffusion, electron self-exchange, and counterion mobility), $C_{\mathrm{o}}$ is the concentration of redox centers, $r$ is the electrode radius, and the rest of the symbols have their usual meaning [16].

In order to translate the above model of charge propagation into the case of borotungstic anions, it is important to perform diagnostic experiments that present the influence of the scan rate, $v$, on the current. The dependence of the voltammetric peak currents on the square root of the scan rate over the full range of scan rates was plotted in Fig. 5. In the scan rate range of 5 $50 \mathrm{~V} \mathrm{~s}^{-1}$, the plot of the voltammetric peak currents versus the square root of the scan rate is linear with an $x$-intercept, whereas at a fast scan rate (no kinetic limitations) a negative deviation from linearity was observed (Fig. 5). This behavior is a clear indication of a

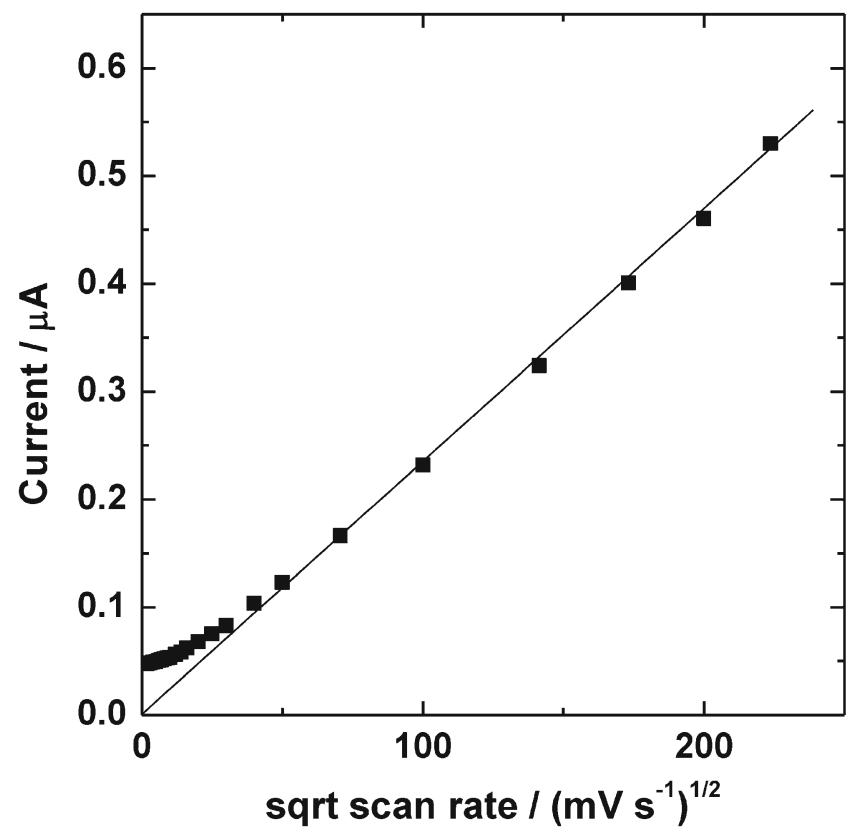

Fig. 5 Dependence of voltammetric peak current on square root of scan rate (plotted for the reduction peak located at ca. $-0.4 \mathrm{~V}$ in Fig. 4) 
linear diffusion regime (perpendicular to the electrode) and can be characterized using the classic Randles-Sevcik equation:

$I_{\mathrm{p}}=2.6910^{-5} n^{3 / 2} A D_{\text {app }}^{1 / 2} C_{\mathrm{o}} v^{1 / 2}$

where $v, C_{\mathrm{o}}, A$, and $n$ denote the scan rate, concentration of redox sites, electrode surface area, and the number of electrons involved, respectively. Moreover, the difference between the position of anodic and cathodic peaks was almost equal to the value predicted by theory $(0.060 \mathrm{~V} /$ electron $)$ in accordance with the definition of a reversible process in classic voltammetry. Moreover, the ratio of the anodic/cathodic peak currents for the first reduction step was 1 . If the scan rate is decreased, purely spherical transport modes (steady-state currents) are recorded, rather than linear diffusion (peaks) (Fig. 4). In consequence, this is reflected in the shape of the recorded voltammogram, which becomes sigmoidal and wave-shaped, as shown in Fig. 4a. In other words, the spherical diffusion field is smaller than the size of the ultramicroelectrode. Moreover, when a low value of the scan rate (below $20 \mathrm{mVs}^{-1}$ ) is used, some deviations are observed where the steady-state plateau currents become independent of the square root of the scan rate (Fig. 5). The results indicated that the uncompensated ohmic drop in the measurement cell is small, and that a fast electron transfer between the electrode and the surface of $\mathrm{BW}_{12}$ single crystal, as well as high dynamics of charge propagation can be observed. This behavior is due to the existence, in the crystallographic structure of $\mathrm{BW}_{12}$, of large amounts of protons (mobile and hydrated) that are promoting fast electron transfer (hopping) between the $\mathrm{W}$ (VI, V) redox sites.

\section{Determination of transport coefficients}

To determine the concentration of redox sites and the diffusion coefficient $\left(C_{\mathrm{o}}\right.$ and $\left.D_{\text {app }}\right)$ from voltammetric data, we used a previously described method [17, 23, 24, 58]. On the basis of two appropriately different scan rates of $50 \mathrm{Vs}^{-1}$ and $4 \mathrm{mVs}^{-1}$ (short-time and long-time regimes), a system of two equations with two variables (the concentration of redox sites and the transport coefficient) were obtained for the results shown in Fig. 4 [22, 25]. Consequently, this allowed us to estimate both parameters: $C_{\mathrm{o}}$ and $D_{\text {app }}$. The following parameters were obtained for 10,25 , and $40 \mu \mathrm{m}$ : $D_{\text {app }}=4.910^{-7} \mathrm{~cm}^{2} \mathrm{~s}^{-1}$ and $C_{\mathrm{o}}=0.46 \mathrm{moldm}^{-3}, D_{\text {app }}=3.4$ $10^{-7} \mathrm{~cm}^{2} \mathrm{~s}^{-1}$ and $C_{\mathrm{o}}=0.58 \mathrm{moldm}^{-3}$, and $D_{\text {app }}=7.710^{-7}$ $\mathrm{cm}^{2} \mathrm{~s}^{-1}$ and $C_{\mathrm{o}}=0.43 \mathrm{moldm}{ }^{-3}$, respectively. In an analogous manner, we combined long-pulse chronoamperometry (spherical diffusion) and short-pulse chronocoulometry (linear diffusion) to determine $C_{\mathrm{o}}$ and $D_{\text {app }}$ [36]. In the doublestep chronoamperometry experiments the initial potential $\left(E_{0}=0 \mathrm{~V}\right)$ was changed instantaneously to the first step potential $\left(E_{1}=-0.5 \mathrm{~V}\right)$ and after first defined time period $(30 \mathrm{~s})$, in the second step, the potential was returned to $E_{2}=$ $0 \mathrm{~V}$ and is held for the second defined time period. The electrolysis potential of $-0.5 \mathrm{~V}$ is approximately $50 \mathrm{mV}$ more negative than the first reduction peak and $50 \mathrm{mV}$ more positive than the second reduction peak, so a one-electron transfer to $\mathrm{BW}_{12}$ is assumed. Figure 6 shows a typical, double-step chronoamperogram obtained for $\mathrm{BW}_{12}$. It should be explained here that the steady-state (plateau) currents $\left(I_{\mathrm{ss}}\right)$ obtained at a slow scan rate (below $4 \mathrm{mV} \mathrm{s}^{-1}$ ), in cyclic voltammetry, is approximately the same, as $I_{\mathrm{ss}}$ obtained in a long-pulse (30 s) chronoamperometry experiment (Fig. 6). In other words, the steady-state currents obtained by cyclic voltammetry were confirmed by chronoamperometry, and it means that in both cases, spherical transport modes are reached. An alternative method to analyze electrochemical data is to plot the cumulative charge $(Q)$ versus times $\left(t^{1 / 2}\right)$ (not show here). In a short-pulse experiment $(16 \mathrm{~ms})$, the plot mentioned above shows a linear dependence according to the integrated formula of the Cottrell equation $[56,57]$ :

$Q=2 n F r^{2} \pi^{1 / 2} D_{\text {app }}{ }^{1 / 2} C_{\mathrm{o}} t^{1 / 2}$

These results imply that the planar diffusion (the diffusion field is small, compared to the electrode radius) becomes predominant in the charge transport mechanism. Moreover, the linearity of the plot could indicate a small or

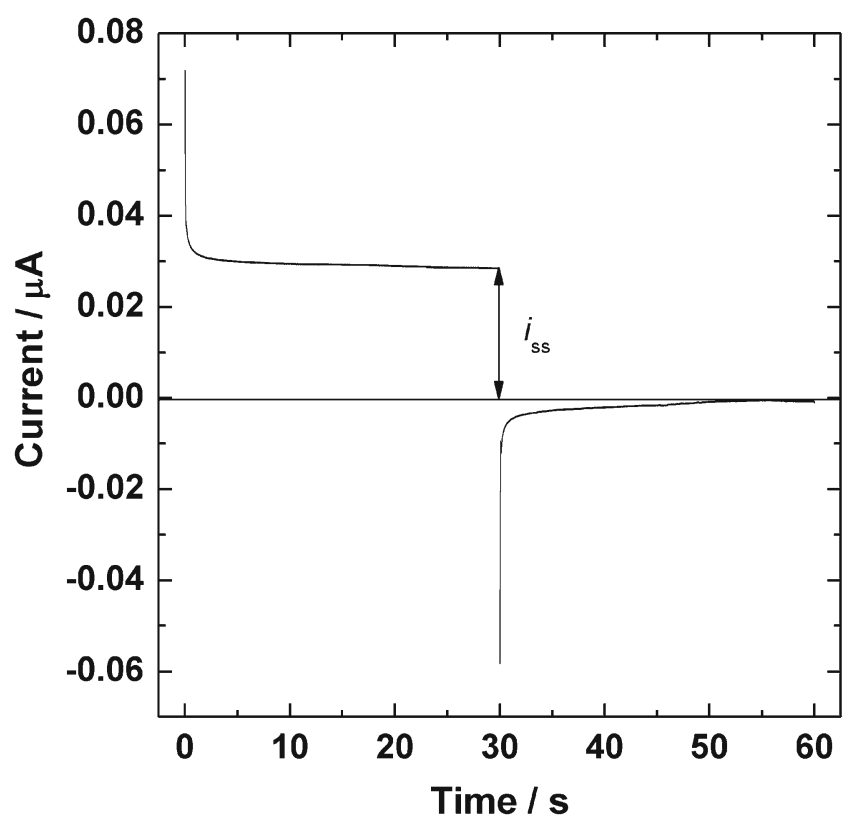

Fig. 6 Double potential step chronoamperometry of $\mathrm{BW}_{12}$. Pulse length, $30 \mathrm{~s}$. The first potential step was from $E_{0}=0.0 \mathrm{~V}$ to $E_{1}=-0.5 \mathrm{~V}$ and the second step from $E_{1}=-0.5 \mathrm{~V}$ to $E_{2}=0.0 \mathrm{~V}$ vs. the $\mathrm{Ag} / \mathrm{Ag}_{2} \mathrm{O}$ pseudoreference electrode. The selected potentials correspond to the first redox system in Fig. 4 
absent ohmic drop, migration, or slow interfacial electron transfer during the measurement $[17,58]$. The following parameters were obtained using this methodology: $10 \mu \mathrm{m}$ $D_{\text {app }}=8.310^{-7} \mathrm{~cm}^{2} \mathrm{~s}^{-1}$ and $C_{\mathrm{o}}=0.23 \mathrm{moldm}^{-3}, 25 \mu \mathrm{m} D_{\text {app }}=$ $7.810^{-7} \mathrm{~cm}^{2} \mathrm{~s}^{-1}$ and $C_{\mathrm{o}}=0.32 \mathrm{moldm}^{-3}$, and $40 \mu \mathrm{m} D_{\text {app }}=$ $8.810^{-7} \mathrm{~cm}^{2} \mathrm{~s}^{-1}$ and $C_{\mathrm{o}}=0.16 \mathrm{moldm}^{-3}$. The results obtained by using a two-regime method (cyclic voltammetric experiments) were compared to the transport coefficient (free of the migration influence) of $\mathrm{BW}_{12}$ by applying a DPSC $[46,47]$. This method gives a unique opportunity to estimate the diffusion coefficient of the electrode reaction product generated in the first chronoamperometric step. We have limited our calculations to the potential range from 0 to $-0.5 \mathrm{~V}$, where the first, most positive voltammetric reduction/oxidation process of $\mathrm{BW}_{12}$ occurs (Fig. 4). The obtained data was used to determine the linearized chronoamperometric responses normalized with respect to the current measured at $t_{\mathrm{g}}=30 \mathrm{~s}$ in the generating step (Fig. 7). The time range used for linearization was $0.1-1 \mathrm{~s}$ for both potential steps. We observed some more or less significant deviations from linearity in the whole range of potential pulses $(30 \mathrm{~s})$. The calculated diffusion coefficient of the substrate and the product are obtained based on the plots of the normalized current of generating and reverse steps, respectively, through incorporating, either the value of the slope, $a$, or the intercept, $b$, of the plots. Values of the diffusion coefficient of the considered $\mathrm{BW}_{12}$ determined using DPSC method were obtained for: $10 \mu \mathrm{m} D_{\mathrm{s}}=1.8$ $10^{-6} \mathrm{~cm}^{2} \mathrm{~s}^{-1}$ and $D_{\mathrm{p}}=1.710^{-6} \mathrm{~cm}^{2} \mathrm{~s}^{-1}, 25 \mu \mathrm{m} D_{\mathrm{s}}=2.910^{-6}$ $\mathrm{cm}^{2} \mathrm{~s}^{-1}$ and $D_{\mathrm{p}}=2.510^{-6} \mathrm{~cm}^{2} \mathrm{~s}^{-1}$, and $40 \mu \mathrm{m} D_{\mathrm{s}}=3.010^{-6}$ $\mathrm{cm}^{2} \mathrm{~s}^{-1}$ and $D_{\mathrm{p}}=2.110^{-6} \mathrm{~cm}^{2} \mathrm{~s}^{-1}$. The results obtained with DPSC method show that the diffusion coefficient of the product is lower than that of the substrate. This result is in a good agreement with the results reported for different heteropolytungstates and materials containing heteropolyanions $[25,47]$.

\section{Conclusions}

This study seems to provide reliable information about the dynamics of bulk charge propagation in $\mathrm{BW}_{12}$ single crystals and the heterogeneous kinetics of interfacial electron transfer. The obtained values of transport coefficients (mixed regimes method) and diffusion coefficients (DPSC) are similar. Neither of the two methods used in this paper can be called superior. They are complimentary. Our study shows that $\mathrm{BW}_{12}$ crystals are characterized by a large population of redox sites, a high effective diffusion coefficient for mass transfer, and a fairly high-standard heterogeneous rate constant for electron transfer at the electrode/crystal interface. It is noteworthy that $\mathrm{BW}_{12}$ shows two reversible, one-
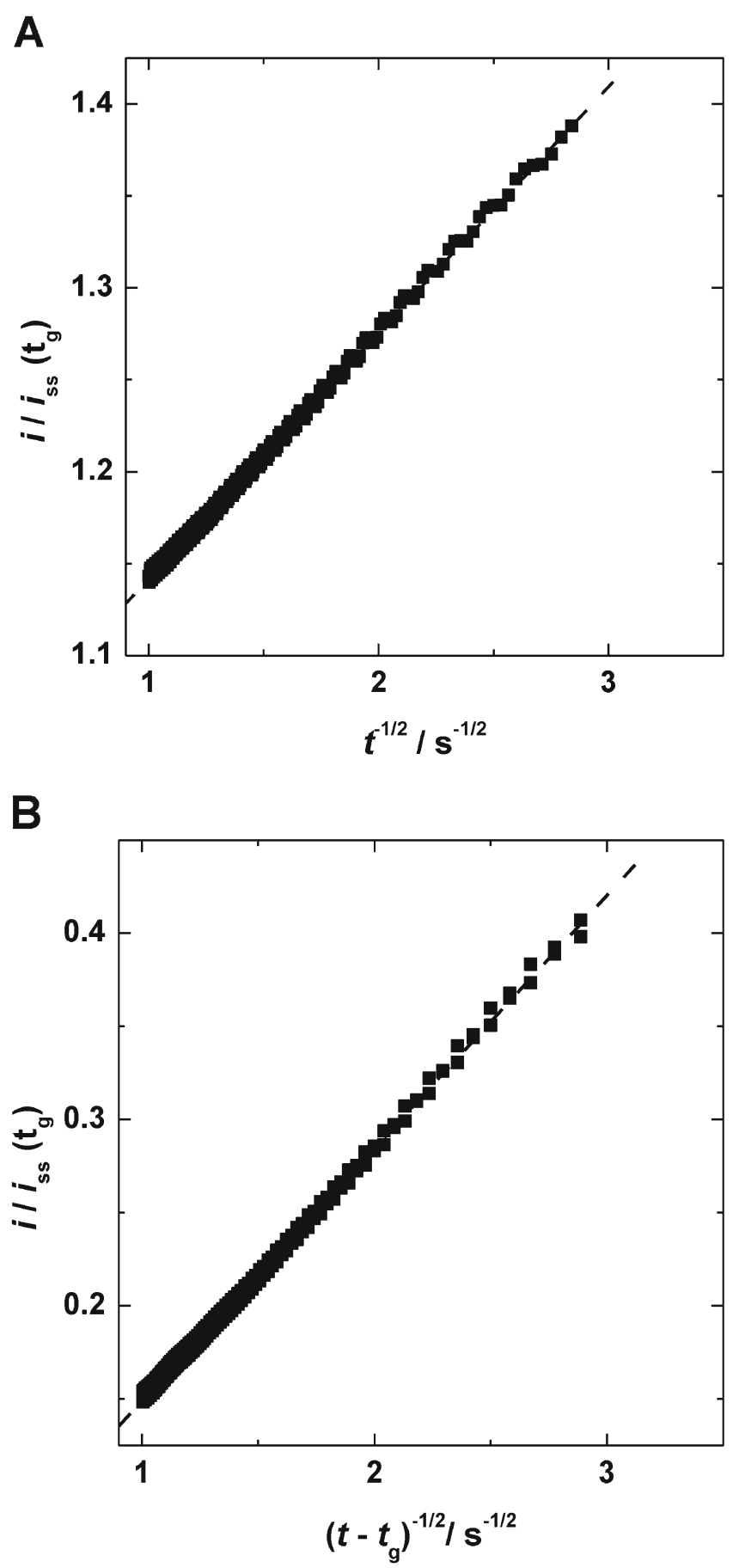

Fig. 7 Normalized chronoamperometric currents for generating (a) and reverse (b) steps plotted against $t^{-1 / 2}$ and $\left(t-t_{\mathrm{g}}\right)^{-1 / 2}$, respectively. Normalizing factor: limiting current measured at $t_{\mathrm{g}}=30 \mathrm{~s}$ in the generating step

electron reactions occurring at relatively negative potentials, and the mechanism of charge transport in the single crystal closely resembles the model of electron hopping promoted by mobile protons, rather than classic diffusion. These parameters are critical to the success of solid-state electrochemical measurements. 
Acknowledgments The authors gratefully acknowledge the support by the National Science Centre (Poland), project no. 2011/03/B/ST4/02413.

Open Access This article is distributed under the terms of the Creative Commons Attribution License which permits any use, distribution, and reproduction in any medium, provided the original author(s) and the source are credited.

\section{References}

1. Katsoulis DE (1998) Chem Rev 98:359-387

2. Pope MT, Muller A (2001) Polyoxometallate chemistry from topology via self-assembly to applications. Kluwer Academic Publishers, Dordrecht

3. Gomez-Romero P (2001) Adv Mater 13:163-174

4. Liu S, Kurth DG, Mohwald H, Volkmer D (2002) Adv Mater $14: 225-228$

5. Adamczyk L, Kulesza PJ (2011) Electrochim Acta 56:3649-3655

6. Adamczyk L, Kulesza PJ, Miecznikowski K, Palys B, Chojak M, Krawczyk D (2005) J Electrochem Soc 152:E98-E103

7. Liu J, Mei W-J, Xu A-W, Tan C-P, Shi S, Ji L-N (2004) Antivir Res 62:65-71

8. Kulesza PJ, Karnicka K, Miecznikowski K, Chojak M, Kolary A, Barczuk PJ, Tsirlina G, Czerwinski W (2005) Electrochim Acta 50:5155-5162

9. Barczuk PJ, Lewera A, Miecznikowski K, Zurowski A, Kulesza PJ (2010) J Power Sources 195:2507-2513

10. Kim YS, Wang F, Hickner M, Zawodzinski TA, McGrath JE (2003) J Membr Science 212:263-282

11. Ramani V, Kunz HR, Fenton JM (2004) J Membr Science 232:31-44

12. Maiyalagan T, Viswanathan B (2008) J Power Sources 175:789-793

13. Stanis RJ, Kuo M-C, Turner JA, Herring AM (2008) J Electrochem Soc 155:B155-B162

14. Ferrell JR III, Kuo M-C, Turner JA, Herring AM (2008) Electrochim Acta 53:4927-4933

15. Stanis RJ, Kuo M-C, Turner JA, Herring AM (2008) Electrochim Acta 53:8277-8286

16. Kulesza PJ, Malik MA (1999) Solid-State Voltammetry. In: Wieckowski A (ed) Interfacial Electrochemistry, Theory, Experiment and Applications. Marcel Dekker, New York, pp 673-688

17. Kulesza PJ, Cox JA (1998) Electroanalysis 10:73-80

18. Chidsey CED, Murray RW (1986) Science 231:25-31

19. Dalton EF, Surridge NA, Jernigan JC, Wilbourn KO, Facci JS, Murray RW (1990) Chem Phys 141:143-157

20. Surridge NA, Jernigan JC, Dalton EF, Buck RP, Watanabe M, Zhang H, Pinkerton M, Wooster TT, Longmire ML, Facci JS, Murray RW (1989) Faraday Discuss Chem Soc 88:1

21. Kulesza PJ, Karwowska B (1996) J Electroanal Chem 401:201-206

22. Kulesza PJ, Karwowska B, Malik MA (1998) Colloids Surf A 134:173-179

23. Holmstrom SD, Karwowska B, Cox JA, Kulesza PJ (1998) J Electroanal Chem 456:239-243

24. Cox JA, Wolkiewicz A, Kulesza PJ (1998) J Solid State Electrochem 2:247-252

25. Lewera A, Miecznikowski K, Chojak M, Makowski O, Golimowski J, Kulesza PJ (2004) Anal Chem 76:2694-2699
26. Lewera A, Chojak M, Miecznikowski K, Kulesza PJ (2005) Electroanalysis $17: 1471-1476$

27. Pope MT (2004) Polyoxoanions: synthesis and structure. In: Wedd AG (ed) Comprehensive coordination chemistry II, vol 4. Elsevier, New York, pp 635-675

28. Kuhn A, Anson FC (1996) Langmuir 12:5481-5488

29. Kulesza PJ, Chojak M, Miecznikowski K, Lewera A, Malik MA, Kuhn A (2002) Electrochem Commun 4:510-515

30. Muzart J (2006) Adv Synth Catal 348:275-295

31. Conte V, Floris B, Galloni P, Silvagni A (2005) Pure Appl Chem $77: 1575-1581$

32. Conte V, Floris B, Galloni P, Silvagni A (2005) Adv Synth Catal 347:1341-1344

33. Miao W, Chan TH (2006) Acc Chem Res 39:897-908

34. Sun LS, Ca DV, Cox JA (2005) J Solid State Electrochem 9:816-822

35. Karnicka K, Chojak M, Miecznikowski K, Skunik M, Baranowska B, Kolary A, Piranska A, Palys B, Adamczyk L, Kulesza PJ (2005) Bioelectrochemistry 66:79-87

36. Kulesza PJ, Faulkner LR (1993) J Am Chem Soc 115:1187811884

37. Bidan G, Genies EM, Lapkowski M (1989) Synth Met 31:327-334

38. Keita B, Essaadi K, Nadjo L (1989) J Electroanal Chem 259:127146

39. Fabre B, Bidan G, Lapkowski M (1994) J Chem Soc Chem Commun 12:1509-1511

40. Cheng L, Cox JA (2001) Electrochem Commun 3:285-289

41. Liu JY, Cheng L, Liu B, Dong S (2001) Electroanalysis 13:993998

42. Fletcher H, Allen CC, Burns RC, Craig DC (2001) Acta Crystallogr Sect C 57:505-507

43. Couto A, Trovao C, Rocha J, Cavaleiro AM, Dejesus JD (1994) J Chem Soc Dalton Trans 17:2585-2586

44. Leclerc-Laronze N, Marrot J, Herv G, Thouvenot R, Cadot E (2007) Chem Eur J 13:7234-7245

45. Miecznikowki K, Cox JA, Lewera A, Kulesza PJ (2000) J Solid State Electrochem 4:199-204

46. Hyk W, Nowicka A, Stojek Z (2002) Anal Chem 74:149-157

47. Caban K, Lewera A, Zukowska GZ, Kulesza PJ, Stojek Z, Jeffrey KR (2006) Anal Chimica Acta 575:144-150

48. Teze A, Michelon M, Herv G (1997) Inorg Chem 36:5666-5669

49. Zhao J, Song Y, Ma P, Wang J, Niu J (2009) J Solid State Chem 182:1798-1805

50. Niua J, Zhaoa J, Wanga J, Maa P (2004) J Mol Struct 699:85-92

51. Wang J-P, Guo G-L, Niu J-Y (2008) J Mol Struct 885:161-167

52. Fu H, Chen W, Wang E, Liu J, Chang S (2009) Inorg Chimica Acta 362:1412-1420

53. Rusu M, Rusu D, Ros C, Craciun C, David L, Toms AR, Marcua G (2000) J Radioanal Nuclear Chem 245:363-366

54. An H, Zheng H, Xu T, He C, Wang J, Wu P, Duan C (2010) Z Anorg Allg Chem 636:2016-2021

55. Wua Q, Maa PT, Songa YP, Wanga JP, Niua JY (2011) Rus J Coord Chem 37:399-403

56. Bard AJ, Faulkner LR (2001) Electrochemical methods, fundamentals and applications. Wiley, New York

57. Inzelt G (2002) Kinetics of electrochemical reactions. In: Scholz F (ed) Electroanalytical methodes guide to experiments and applications. Springer, Berlin, pp 29-47

58. Aoki K, Osteryoung J (1984) J Electroanal Chem 160:335-339 